\title{
Relationship between the Association Constant and Enantioselectivity on the Flavoprotein-Conjugated Chiral Stationary Phase for High-Performance Liquid Chromatography
}

\author{
Nariyasu Mano ${ }^{\dagger}$, Yasushi Ishinama, Yoshiya Oda and Naoki Asakawa \\ Analytical Chemistry and Pharmaceutical Research Section, Tsukuba Research Laboratories, Eisai Co., Ltd., \\ Tokodai, Tsukuba 300-26, Japan
}

\begin{abstract}
The relationship between the enantioselectivity and association constants of enantiomers on high-performance liquid chromatography with a protein-conjugated chiral stationary phase (CSP) was investigated using a flavoproteinconjugated CSP, with ketoprofen (KP) as a model drug. The association constants of the enantiomers for native flavoprotein were different; it has been found that they contribute to the chiral separation on a protein CSP. Equations including the association constants were developed to calculate, the capacity factors and enantioselectivities on protein CSPs; they were validated by means of experiments using a flavoprotein column in combination with variable numbers of non-specific columns in series. The capacity factors and enantioselectivities calculated with the developed equations showed reasonable agreement with those obtained by chromatography employing a conventional flavoprotein column $(150 \mathrm{~mm} \times 4.6 \mathrm{~mm}$ i.d.) with a mobile phase containing methanol as an organic modifier. Our results imply that proteinconjugated CSPs are complex-stationary phases consisting of both a specific phase for chiral separation and a non-specific phase, and that the resolution of the enantiomers depends upon the balance of interactions of solute molecules with the two phases.
\end{abstract}

Keywords High-performance liquid chromatography, protein-conjugated column, complex-stationary phase, association constant, capacity factor, enantioselectivity

Protein-conjugated chiral stationary phases $(\mathrm{CSPs})^{1-6}$ can separate many enantiomers ${ }^{7}$ with an aqueous mobile phase; they have been employed for the analysis of drug enantiomers in biological materials. ${ }^{8-12}$ The enantioseparation by protein CSPs is greatly influenced by the mobile-phase conditions, such as organic modifiers, buffer salts and $\mathrm{pH}^{5-6,13}$, because these factors influence the state of the protein surface. Wainer and co-workers found a linear relation between the retention $\left(k^{\prime} /\left(k^{\prime}+1\right)\right)$ and protein-binding capacity using a series of analogues. ${ }^{14,15}$ We investigated the effect of protein binding on the retention and chiral separation by using 4 different protein CSPs (ovomucoid, avidin, conalbumin and flavoprotein). ${ }^{16}$ The retention increased with an increase in the binding capacity, and the enantioselectivity increased with an increase in the difference of binding between enantiomers.

Enzymes can highly discriminate drug enantiomers; this fact contributes to the differences of metabolism and biological activity between enantiomers. ${ }^{17}$ Since chiral discrimination by enzymes is due to differences in the affinity of drug enantiomers for binding sites on the enzyme protein, we considered that chiral separations on protein CSPs might be described by a general equation including the association constants.

\footnotetext{
$\dagger$ To whom correspondence should be addressed.
}

We present here theoretical equations for calculating the capacity factor $\left(k^{\prime}\right)$ and enantioselectivity $(\alpha)$ of protein CSPs. Their validity was supported by experiments using a flavoprotein (FLA)-conjugated column in combination with variable numbers of nonspecific columns (NSP) in series. In addition, when methanolic mobile phases were used on a conventional FLA column ( $150 \mathrm{~mm} \times 4.6 \mathrm{~mm}$ i.d.), the $k^{\prime}$ and $\alpha$ values calculated using the developed equations showed reasonable agreement with the experimental $k^{\prime}$ and $\alpha$ values.

\section{Experimental}

\section{Column}

FLA-CSP was prepared by our method. ${ }^{6}$ The amount of immobilized FLA was determined by a protein assay ${ }^{18}$ of the amount of unreacted protein after the immobilization procedure. FLA-CSP columns with dimensions of $10 \mathrm{~mm} \times 4.0 \mathrm{~mm}$ i.d. and $150 \mathrm{~mm} \times$ $4.6 \mathrm{~mm}$ i.d. were prepared by a conventional slurry packing procedure. NSP columns $(10 \mathrm{~mm} \times 4.0 \mathrm{~mm}$ i.d. and $150 \mathrm{~mm} \times 4.6 \mathrm{~mm}$ i.d.) were prepared by the activation of aminopropyl silica gel with $N, N$-disuccinimidyl carbonate (DSC). 


\section{Apparatus}

The HPLC pump was a CCPM multi pump with a PX-1080 controller (TOSOH, Tokyo, Japan). All injections were carried out using a Model 712 autosampler (Waters, USA). The detector was an SPD-10A UV photometric detector (Shimadzu, Kyoto, Japan).

\section{Chemicals}

Ketoprofen (KP) was purchased from Sigma (St. Louis, MO, USA). Naproxen was from Aldrich (Milwaukee, WI, USA). $N, N$-Disuccinimidyl carbonate was from Wako (Osaka, Japan). Nucleosil $5 \mathrm{NH}_{2}$ was from Macherey-Nagel (Düren, Germany). All other chemicals and solvents were of analytical grade.

\section{Chromatography}

All of the experiments were carried out at $24-27^{\circ} \mathrm{C}$. The amount of KP injected was $40 \mathrm{ng} / 5 \mu \mathrm{l}$ (minicolumn experiment), or $200 \mathrm{ng} / 5 \mu \mathrm{l}$ (conventional column experiment) as the racemate. The detection wavelength was $254 \mathrm{~nm}$. The flow rate was $0.5 \mathrm{ml} / \mathrm{min}(10 \mathrm{~mm} \times 40$ $\mathrm{mm}$ i.d.) or $1.0 \mathrm{ml} / \mathrm{ml}(150 \mathrm{~mm} \times 4.6 \mathrm{~mm}$ i.d. $)$. The mobile phase volume $\left(V_{\mathrm{m}}\right.$ and $\left.V_{\mathrm{m}}{ }^{\prime}\right)$ and void volume $\left(V_{0}\right)$ were determined by injection of methanol.

\section{Scatchard plot}

A solution of a known amount of racemic KP solution was diluted with water, and $50 \mu 1$ aliquots were added to a flavoprotein solution $(10 \mathrm{mg} / 0.5 \mathrm{ml}$ of $20 \mathrm{mM}$ potassium phosphate buffer). The solution was adjusted to $1.0 \mathrm{ml}$ with a buffer or buffer/methanol mixture, and incubated at $25^{\circ} \mathrm{C}$ for $1 \mathrm{~h}$. After ultrafiltration using an ULTRACENT-10 (molecular cut-off 10000, TOSOH), $100 \mu \mathrm{l}$ of the filtrate and naproxen solution $(2.5 \mu \mathrm{g} /$ $100 \mu \mathrm{l})$ as an internal standard were mixed and analyzed with a chiral separation column, ULTRON ESOVM (150 mm $\times$ $4.6 \mathrm{~mm}$ i.d., Shinwa Chemical Industries Ltd., Kyoto) using $20 \mathrm{mM}$ potassium phosphate buffer ( $\mathrm{pH} \mathrm{3.0)/}$ acetonitrile $(10: 1)$ at a flow-rate of $1.0 \mathrm{ml} / \mathrm{min}$.

\section{Theory and Results}

The interactions of solutes with protein CSPs are considered to be as illustrated in Fig. 1. The solute interacts not only with specific binding sites on a protein molecule, but also with non-specific regions, such as the surface of the silica support, the aminopropyl spacer and DSC residues. These interactions can be summarized as follows:

$$
\mathrm{S}_{\mathrm{nsp}} \stackrel{K_{\mathrm{nsp}}}{\rightleftharpoons} \mathrm{S}_{\mathrm{m}} \stackrel{K_{\mathrm{pro}}}{\rightleftharpoons} \mathrm{S}_{\mathrm{pro}}
$$

where $S_{\mathrm{nsp}}, S_{\mathrm{m}}$ and $S_{\text {pro }}$ represent solute molecules binding to the non-specific phase, free solute molecules and the solute molecules binding to protein molecules, respectively. $K_{\text {nsp }}\left(K_{\text {nsp }}=[\mathrm{S}]_{\text {nsp }} /[\mathrm{S}]_{\mathrm{m}}\right)$ and $K_{\text {pro }}\left(K_{\text {pro }}=\right.$ $\left.[\mathrm{S}]_{\text {pro }} /[\mathrm{S}]_{\mathrm{m}}\right)$ are the distribution constant of solute mole-

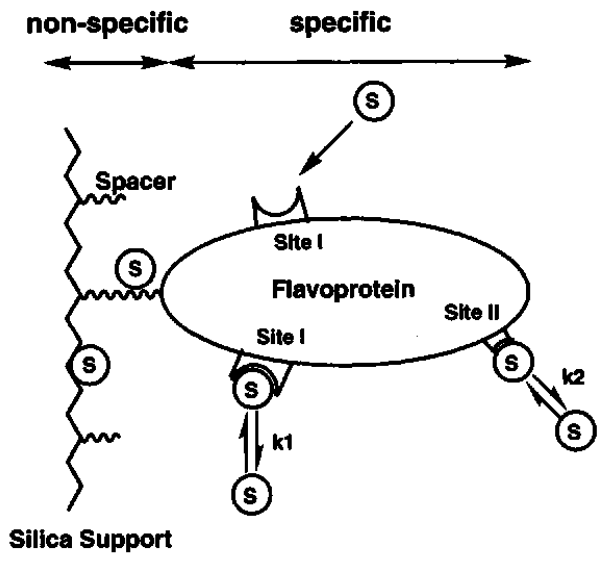

Fig. 1 Schematic illustration of the interactions of solute molecules with a protein-conjugated chiral stationary phase. $\mathrm{s}$, solute molecules in the columns; site I, higher-affinity site for solute molecules on the protein molecule; site II, loweraffinity site for solute molecules on the protein molecule.

cules for the non-specific phase and that for the protein phase, respectively. The capacity factor is expressed by $k^{\prime}=K_{\mathrm{s}} \cdot V_{\mathrm{s}} / V_{\mathrm{m}}$ in conventional chromatography $\left(K_{\mathrm{s}}\right.$ is the distribution constant of solute for the stationary phase, $V_{\mathrm{s}}$ is the stationary phase volume and $V_{\mathrm{m}}$ is the mobile phase volume). The $k^{\prime}$ value on protein CSP therefore is given by

$$
k_{\mathrm{csp}}^{\prime}=k_{\mathrm{pro}}^{\prime}+k_{\mathrm{nsp}}^{\prime}=\frac{K_{\mathrm{pro}} \cdot V_{\mathrm{pro}}+K_{\mathrm{nsp}} \cdot V_{\mathrm{nsp}}}{V_{\mathrm{m}}},
$$

where $V_{\text {pro }}$ and $V_{\text {nsp }}$ are the volume of the protein and that of the non-specific regions in the column. On the other hand, the following equilibrium relationship applies between the solute and protein in aqueous solution:

$$
\mathrm{P}+\mathrm{S} \stackrel{K_{\mathrm{p}}}{\rightleftharpoons} \mathrm{PS}
$$

where the association constant $\left(K_{\mathrm{p}}\right)$ of the solute molecules for the protein molecules is [PS]/([S] [P]). The binding behavior of immobilized HSA has been found to be similar to that seen for HSA in solution; ${ }^{19,20}$ this result implies that the immobilized protein exists in a similar environment to that of the free protein in solution. If the degree of freedom of the immobilized protein molecules is similar to that of free protein molecules in aqueous solution, the immobilized protein molecules can be regarded as being dissolved in the mobile phase. If this hypothesis is valid, $[\mathrm{PS}] /[\mathrm{S}]$ is equal to $[\mathrm{S}]_{\mathrm{pro}} /[\mathrm{S}]_{\mathrm{m}}$, and the distribution constant of solute for the protein regions $\left(K_{\text {pro }}\right)$ can be expressed as $K_{\mathrm{p}} \cdot[\mathrm{P}]$ ([P] is the molar concentration of protein molecules in the mobile phase). Then, according to Eq. (2), the $k^{\prime}$ value on a protein CSP is given by 
Table 1 Effect of non-specific interaction on capacity factor and enantioselectivity

\begin{tabular}{cccccccc}
\hline \multirow{2}{*}{ NSP } & \multicolumn{3}{c}{$\mathrm{pH} \mathrm{4.0}$} & & \multicolumn{3}{c}{$\mathrm{pH} 5.0$} \\
\cline { 2 - 4 } \cline { 5 - 7 } & $k_{1}^{\prime}$ & $k_{2}^{\prime}$ & $\alpha$ & & $k_{1}^{\prime}$ & $k_{2}^{\prime}$ & $\alpha$ \\
\hline
\end{tabular}

(a) Experimental values

$\begin{array}{lllllll}0 & 24.08 & 33.00 & 1.37 & 15.23 & 19.47 & 1.28 \\ 1 & 24.10 & 29.85 & 1.24 & 16.21 & 19.03 & 1.17 \\ 2 & 24.30 & 28.85 & 1.19 & 17.92 & 19.63 & 1.10 \\ 3 & 25.32 & 28.19 & 1.11 & 18.33 & 19.77 & 1.08 \\ 4 & 25.22 & 27.90 & 1.11 & 19.42 & 20.60 & 1.06\end{array}$

Chromatographic conditions: mobile phase, $20 \mathrm{mM}$ potassium phosphate buffer; flow rate, $0.5 \mathrm{ml} / \mathrm{min}$; detection, UV $254 \mathrm{~nm}$; injection amount, $40 \mathrm{ng} / 5 \mu \mathrm{l}$.

(b) Calculated values

$\begin{array}{lllllll}0 & 24.06 & 32.95 & 1.37 & 15.20 & 19.23 & 1.26 \\ 1 & 24.07 & 30.29 & 1.26 & 16.33 & 19.42 & 1.19 \\ 2 & 24.36 & 28.96 & 1.19 & 17.33 & 19.79 & 1.14 \\ 3 & 24.74 & 28.27 & 1.14 & 18.23 & 20.22 & 1.11 \\ 4 & 25.13 & 27.93 & 1.11 & 19.01 & 20.67 & 1.09\end{array}$

Calculated values by using Eqs. (6) and (7) in the text.

$\mathrm{NSP}=$ number $(n)$ of non-specific columns.

$k_{1}^{\prime}=$ capacity factor of first-eluted enantiomer of KP.

$k_{2}^{\prime}=$ capacity factor of second-eluted enantiomer of KP.

$\alpha=$ enantioselectivity.

$$
k_{\mathrm{csp}}^{\prime}=\frac{K_{\mathrm{p}} \cdot[\mathrm{P}] \cdot V_{\mathrm{pro}}+K_{\mathrm{nsp}} \cdot V_{\mathrm{nsp}}}{V_{\mathrm{m}}}
$$

Further, the enantioselectivity ( $\alpha$ ) is expressed by

$$
\alpha=\frac{K_{\mathrm{p} 2} \cdot[\mathrm{P}] \cdot V_{\mathrm{pro}}+K_{\mathrm{nsp}} \cdot V_{\mathrm{nsp}}}{K_{\mathrm{p} 1} \cdot[\mathrm{P}] \cdot V_{\mathrm{pro}}+K_{\mathrm{nsp}} \cdot V_{\mathrm{nsp}}}
$$

These equations show that the $k^{\prime}$ and $\alpha$ values are influenced by the association constant, because [P], $V_{\text {pro, }}$, $V_{\text {nsp }}, V_{\mathrm{m}}$ and $K_{\text {nsp }}$ are the eigenvalues for a column.

To test the validity of these equations, the relationship between the $k^{\prime}$ values and the amounts of the non-specific phase was investigated using a system consisting of an FLA-CSP minicolumn (10 $\mathrm{mm} \times 4.0 \mathrm{~mm}$ i.d. $)$ in combination with various numbers of NSP minicolumns $(10 \mathrm{~mm} \times 4.0 \mathrm{~mm}$ i.d.) in series. The same amount of KP enantiomers was injected with different numbers of NSP columns, and each $k^{\prime}$ value was determined. The results are shown in Table 1(a), and typical chromatograms in Fig. 2. At both pH 4.0 and pH 5.0, an increment of the non-specific interaction increase in the number of NSP columns resulted in a lowering of the enantioselectivity.

It should be noted that increasing the number of nonspecific columns increases the mobile-phase volume. Because [P] in Eqs. (4) and (5) is the molar concentration of protein molecules in the mobile phase, it varies with a change in the number $(n)$ of NSP minicolumns combined with the FLA-CSP minicolumn, as given in (a) pH 4.0

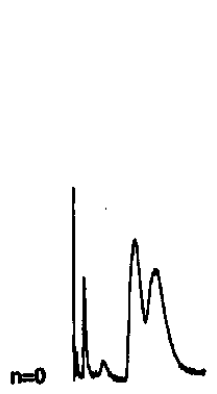

$\ln _{n=1}^{M}$
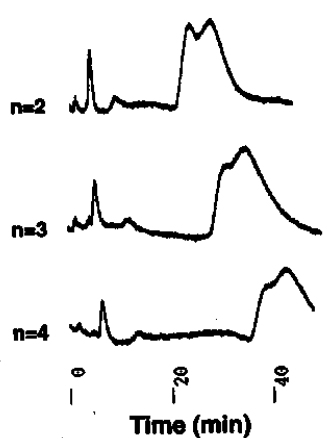

(b) pH $\mathbf{5 . 0}$

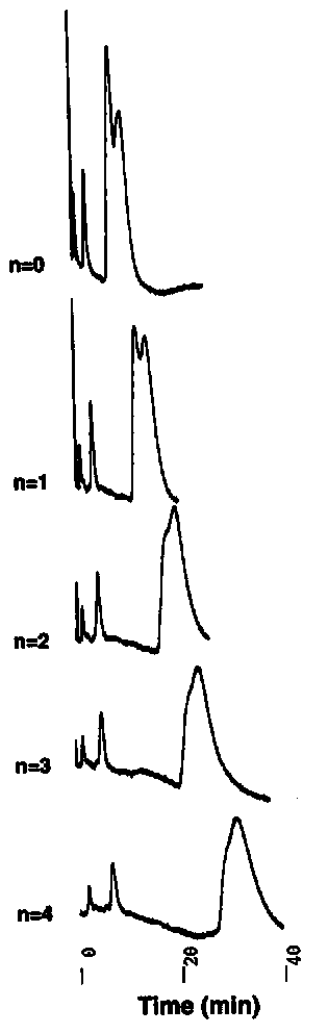

Fig. 2 Chromatograms obtained in minicolumn experiments. An FLA-CSP minicolumn was used in combination with various numbers $(n=0-4)$ of NSP minicolumns. Chromatographic conditions: mobile phase, $20 \mathrm{mM}$

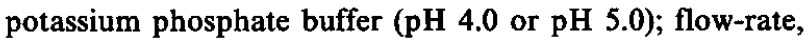
$0.5 \mathrm{ml} / \mathrm{min}$; UV detection wavelength, $254 \mathrm{~nm}$; column temperature, $25^{\circ} \mathrm{C}$; injection amount, $40 \mathrm{ng} / 5 \mu \mathrm{l}$ as racemate.

$$
[\mathrm{P}]=\frac{S}{V_{\mathrm{m}}+n \cdot V_{\mathrm{m}}^{\prime}}
$$

where $V_{\mathrm{m}}^{\prime}$ is the mobile phase volume in the NSP minicolumns and $S$ is the molar amount of protein molecules immobilized on the silica support. On the other hand, the non-specific phase volume is expressed as $V_{\text {nsp }}+n \cdot V_{\text {nsp }}^{\prime}$, where $V_{\text {nsp }}^{\prime}$ is the volume of non-specific regions in the NSP columns. Thus, Eqs. (4) and (5) are modified as follows in the case of the combination of FLA-CSP with NSP columns in series:

$$
k_{\mathrm{csp}}^{\prime}=\frac{\frac{K_{\mathrm{p}} \cdot S \cdot V_{\mathrm{pro}}}{V_{\mathrm{m}}+n \cdot V_{\mathrm{m}}^{\prime}}+K_{\mathrm{nsp}} \cdot\left(V_{\mathrm{nsp}}+n \cdot V_{\mathrm{nsp}}^{\prime}\right)}{V_{\mathrm{m}}+n \cdot V_{\mathrm{m}}^{\prime}}
$$

and

$$
\alpha=\frac{\frac{K_{\mathrm{p} 2} \cdot S \cdot V_{\mathrm{pro}}}{V_{\mathrm{m}}+n \cdot V_{\mathrm{m}}^{\prime}}+K_{\mathrm{nsp}} \cdot\left(V_{\mathrm{nsp}}+n \cdot V_{\mathrm{nsp}}^{\prime}\right)}{\frac{K_{\mathrm{p} 1} \cdot S \cdot V_{\mathrm{pro}}}{V_{\mathrm{m}}+n \cdot V_{\mathrm{m}}^{\prime}}+K_{\mathrm{nsp}} \cdot\left(V_{\mathrm{nsp}}+n \cdot V_{\mathrm{nsp}}^{\prime}\right)} .
$$


The association constant $\left(K_{\mathrm{p}}\right)$ of each enantiomer in the presence of the opposite enantiomer was determined by a Scatchard-plot analysis (Table 3). The association constant of the second-eluted enantiomer of KP was higher than that of the first-eluted enantiomer. The $k^{\prime}$ values calculated using Eq. (7) agreed very closely with those obtained by experiment (Table 1), and the $\alpha$ values obtained by experiment showed a good correlation $(\mathrm{pH}$ $4.0 ; r^{2}=0.9682$, pH 5.0; $r^{2}=0.9571$ ) with those calculated using Eq. (8). All of the parameters for the calculation used in the minicolumn experiment are summarized in Table 2.

Next, we investigated the $k^{\prime}$ and $\alpha$ values using a mobile phase containing methanol on a conventional FLA-CSP column $(150 \mathrm{~mm} \times 4.6 \mathrm{~mm}$ i.d.). Typical chromatograms are shown in Fig. 3. Table 3 lists the association constants of each KP enantiomer in the presence of the opposite enantiomer for a native flavoprotein in a solution containing methanol. For both enantiomers, the $K_{\mathrm{p}}$ values decreased with an increase in the methanol content. The $k^{\prime}$ and $\alpha$ values calculated with Eqs. (4)

Table 2 Parameters for calculation of $k^{\prime}$ and $\alpha$ values for the minicolumn experiment

\begin{tabular}{lll}
\hline & $\mathrm{pH} 4.0$ & \multicolumn{1}{c}{$\mathrm{pH} \mathrm{5.0}$} \\
\hline$S$ & $3.6 \times 10^{-7}(\mathrm{~mol})$ & $3.6 \times 10^{-7}(\mathrm{~mol})$ \\
$V_{\text {pro }}$ & $8.1 \times 10^{-10}(1)$ & $3.8 \times 10^{-10}(1)$ \\
$V_{\mathrm{m}}$ & $5.5 \times 10^{-7}(1)$ & $4.7 \times 10^{-7}(1)$ \\
$V_{\mathrm{m}}^{\prime}$ & $1.1 \times 10^{-7}(1)$ & $6.7 \times 10^{-8}(1)$ \\
$k_{\text {nsp }}^{\prime}$ & 9.84 & 8.22 \\
\hline
\end{tabular}

Table 3 Association constants of each enantiomer

\begin{tabular}{cccc}
\hline $\mathrm{pH}$ & $\mathrm{MeOH}, \%$ & $K_{\mathrm{p} 1} / 10^{-4} \mathrm{M}^{-1}$ & $K_{\mathrm{p} 2} / 10^{-4} \mathrm{M}^{-1}$ \\
\hline 4.0 & 0 & 0.87 & 3.28 \\
4.0 & 2 & 0.60 & 1.11 \\
4.0 & 5 & 0.39 & 0.72 \\
4.0 & 10 & 0.32 & 0.45 \\
4.0 & 15 & 0.12 & 0.16 \\
5.0 & 0 & 1.00 & 1.65 \\
\hline
\end{tabular}

$K_{\mathrm{p} 1}=$ association constant of first-eluted enantiomer of KP. $K_{\mathbf{p} 2}=$ association constant of second-eluted enantiomer of KP.

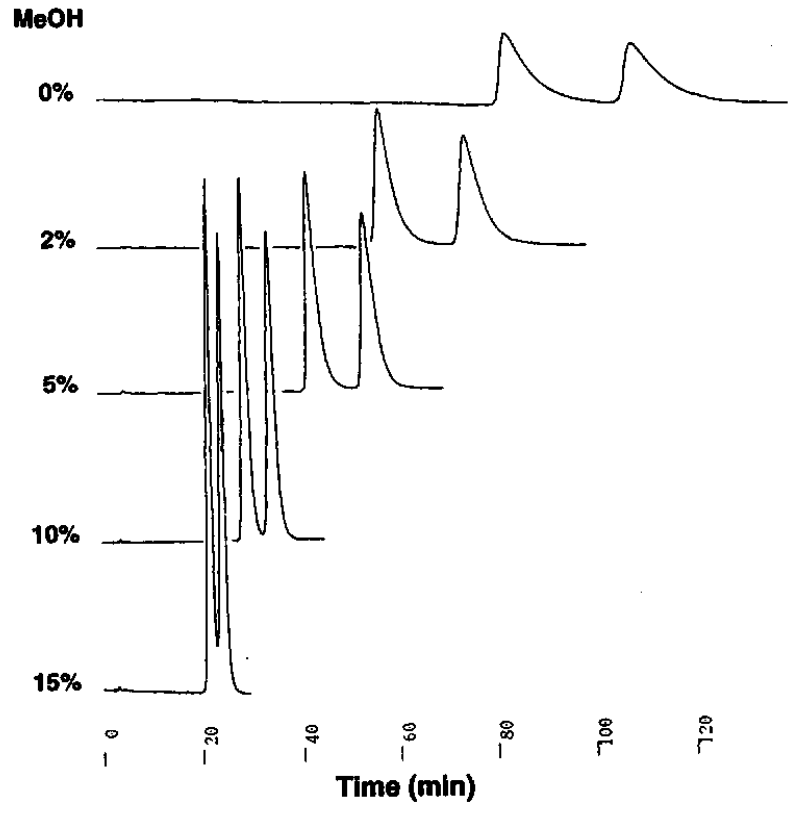

Fig. 3 Chromatograms on a conventional FLA-CSP column. Chromatographic conditions: mobile phase, $20 \mathrm{mM}$ potassium phosphate buffer (pH 4.0)/methanol (100:0, $98: 2,95: 5,90: 10,85: 15)$; flow-rate, $1.0 \mathrm{ml} / \mathrm{min}$; UV detection wavelength, $254 \mathrm{~nm}$; column temperature, $25^{\circ} \mathrm{C}$; injection amount, $200 \mathrm{ng} / 5 \mu \mathrm{l}$ as racemate.

Table 4 Parameters for calculation of $k^{\prime}$ and $\alpha$ values for the conventional FLA-CSP column

\begin{tabular}{lc}
\hline \multicolumn{1}{c}{ Parameter } & Value \\
\hline$[\mathrm{P}]$ & $3.53 \times 10^{-3}(\mathrm{M})$ \\
$V_{\text {pro }}$ & $2.58 \times 10^{-4}(1)$ \\
$V_{\mathrm{m}}$ & $1.81 \times 10^{-3}(1)$ \\
$k_{\text {nsp }}^{\prime}(0 \% \mathrm{MeOH})$ & $41.92 \pm 0.55$ \\
$k_{\text {nsp }}^{\prime}(2 \% \mathrm{MeOH})$ & $23.23 \pm 0.23$ \\
$k_{\text {nsp }}^{\prime}(5 \% \mathrm{MeOH})$ & $14.53 \pm 0.40$ \\
$k_{\text {nsp }}^{\prime}(10 \% \mathrm{MeOH})$ & $7.91 \pm 0.22$ \\
$k_{\text {nsp }}^{\prime}(15 \% \mathrm{MeOH})$ & $5.02 \pm 0.09$ \\
\hline
\end{tabular}

$k_{\text {nsp }}^{\prime}$ values were determined by using a non-specific column with dimensions $150 \mathrm{~mm} \times 4.6 \mathrm{~mm}$ i.d. $(n=3)$ prepared by the conventional slurry packing procedure.

Table 5 Effect of methanol content on capacity factor and enantioselectivity

\begin{tabular}{cccccccc}
\hline \multirow{2}{*}{$\mathrm{MeOH}, \%$} & \multicolumn{3}{c}{ Experimental $^{\mathrm{a}}$} & & \multicolumn{3}{c}{ Calculated $^{\mathrm{b}}$} \\
\cline { 2 - 4 } \cline { 6 - 7 } & \multicolumn{1}{c}{$k_{1}^{\prime}$} & $k_{2}^{\prime}$ & $\alpha$ & & $k_{1}^{\prime}$ & $k_{2}^{\prime}$ & $\alpha$ \\
\hline 0 & $38.44 \pm 0.30$ & $50.55 \pm 0.37$ & 1.32 & 38.95 & 51.06 & 1.31 \\
2 & $27.84 \pm 0.06$ & $36.70 \pm 0.07$ & 1.32 & & 27.66 & 36.52 & 1.32 \\
5 & $20.34 \pm 0.50$ & $25.99 \pm 0.65$ & 1.28 & 19.11 & 24.77 & 1.30 \\
10 & $13.32 \pm 0.28$ & $15.95 \pm 0.33$ & 1.20 & 11.78 & 14.41 & 1.22 \\
15 & $9.27 \pm 0.09$ & $10.49 \pm 0.10$ & 1.13 & & 9.61 & 10.84 & 1.13 \\
\hline
\end{tabular}

a. Experimental values obtained by using the equation $k^{\prime}=\left(t-t_{0}\right) / t_{0}, \alpha=k_{2}^{\prime} / k_{1}^{\prime}$ in the chromatography. b. Calculated values obtained by using Eqs. (4) and (5) in the text. $k_{1}^{\prime}=$ capacity factor of first-eluted enantiomer of KP. $\quad k_{2}^{\prime}=$ capacity factor of second-eluted enantiomer of KP. $\alpha=$ enantioselectivity. Chromatographic conditions: column, flavoprotein-immobilized column ( $150 \mathrm{~mm} \times 4.6 \mathrm{~mm}$ i.d.); mobile phases, $20 \mathrm{mM}$ potassium phosphate buffer (pH 4.0)/methanol (100:0,98:2, 95:5, $90: 10,85: 15)$; flow rate, $1.0 \mathrm{ml} / \mathrm{min}$; detection, UV $254 \mathrm{~nm}$; injection amount, $200 \mathrm{ng} / 5 \mu \mathrm{l}$; number of injection, $n=3$. 
and (5) (Table 4) are in fair agreement with the experimental values (Table 5). These results suggest that the equations for the capacity factor and enantioselectivity are reasonable for considering chiral separation on protein-conjugated columns.

\section{Discussion}

As shown in Table 1, the $\alpha$ values fell with an increase in the number of NSP minicolumns combined with the FLA-CSP minicolumn at both $\mathrm{pH} 4.0$ and $\mathrm{pH}$ 5.0. However, the drop in the $\alpha$ values at $\mathrm{pH} 4.0$ was a consequence of the constant $k_{1}^{\prime}$ values and declining $k_{2}^{\prime}$ values with increment of the non-specific phase, whereas the $k_{1}^{\prime}$ values increased and the $k_{2}^{\prime}$ values remained constant at $\mathrm{pH}$ 5.0. These results show that the specific and non-specific interactions contribute differently to the retention of KP enantiomers at each pH. Equation (2) for calculating the $k^{\prime}$ values shows that $k_{\text {csp }}^{\prime}$ is determined by both $k_{\text {pro }}^{\prime}$ and $k_{\text {nsp. }}^{\prime}$ At pH 4.0, the specific interaction with the protein has a greater effect than the non-specific interaction in the retention of both enantiomers. On the other hand, the ratio of the non-specific interaction at pH 5.0 is greater than that at pH 4.0. When the effect of the non-specific interaction is small, the increase in the retention time with the increase in the number of NSP minicolumns is small, and the $k^{\prime}$ value therefore decreases. On the other hand, an increase in nonspecific interactions results in an increase in the $k^{\prime}$ value. At pH 4.0, a large portion of the solute (KP) exists in a non-ionic form, whereas at $\mathrm{pH} 5.0$ the carboxylic acid moiety of KP is mostly ionized. The ionic interaction of the carboxylic acid moiety in KP may be the predominant factor in the non-specific interaction. The difference in the affinity of the KP enantiomers for protein is greater at $\mathrm{pH} 4.0$ than at $\mathrm{pH} 5.0$, as shown in Table 4 . Thus, the pH 4.0 condition, where the effect of the nonspecific interaction is small and there is a greater difference between the association constants of KP enantiomers for the protein, gave a better resolution than the $\mathrm{pH} 5.0$ condition.

The $K_{\mathrm{p}}$ values given in Table 3 and the $K_{\text {nsp }}$ values in Table 4 suggest that this flavoprotein-conjugated column retained the solute in the reversed-phase mode and that organic modifiers affected both the specific and non-specific interactions. In particular, the association constants of the KP enantiomers for the protein fell remarkably; this fact suggests that a hydrophobic interaction at the chiral discriminative region in the protein molecule is very important for chiral separation. Consequently, the use of a mobile phase without organic modifiers might give the best chiral separation, though the retention time is long and the peaks are broad.

In conclusion, the equations for the capacity factor and enantioselectivity of protein-conjugated CSPs have been developed, and their validity confirmed experimentally by using combinations of flavoprotein and non-specific minicolumns in series. The capacity factors and enantioselectivity for KP were also calculated for a conventional flavoprotein column ( $150 \mathrm{~mm} \times 4.6 \mathrm{~mm}$ i.d.) with a methanolic mobile phase; the calculated results agreed reasonably well with the experimentally determined values. Overall, the results support the validity of the complex interaction model of the specific and nonspecific interactions shown in Fig. 1. Thus, to understand chiral separation on protein-conjugated CSP we must take into consideration all interactions, including the non-specific interaction. That is to say, the chiral discrimination observed with native proteins is not necessarily be reflected in chromatographic separation, because of the effect of the non-specific interaction.

We thank Mr. Hiroshi Inoue, Kawashima Factory, Eisai Co., Ltd., for the purification and supply of flavoprotein.

\section{References}

1. S. Allenmark, B. Bomgren and H. Boren, J. Chromatogr., 264, 63 (1983).

2. J. Hermansson, J. Chromatogr., 269, 71 (1983).

3. T. Miwa, M. Ichikawa, M. Tsuno, T. Hattori, T. Miyakawa, M. Kayano and Y. Miyake, Chem. Pharm. Bull., 35, 682 (1987).

4. Y. Oda, N. Asakawa, S. Abe, Y. Yoshida and T. Sato, $J$. Chromatogr., 572, 133 (1991).

5. N. Mano, Y. Oda, T. Miwa, N. Asakawa, Y. Yoshida and T. Sato, J. Chromatogr., 603, 105 (1992).

6. N. Mano, Y. Oda, N. Asakawa, Y. Yoshida, T. Sato and T. Miwa, J. Chromatogr., 623, 221 (1992).

7. K. M. Kirkland, K. L. Neilson and D. A. McCombs, $J$. Chromatogr., 545, 43 (1991).

8. Y. Oda, N. Asakawa, T. Kajima, Y. Yoshida and T. Sato, Pharm. Res., 8, 997 (1991).

9. Y. Oda, N. Asakawa, T. Kajima, Y. Yoshida and T. Sato, J. Chromatogr., 541, 411 (1991).

10. Y. Oda, H. Ohe, N. Asakawa, Y. Yoshida, T. Sato and T. Nakagawa, J. Liq. Chromatogr., 15, 2997 (1992).

11. J. J. Butter, J. C. Kraak and H. Poppe, J. Pharm. Biomed. Anal., 11, 225 (1993).

12. N. Mano, Y. Oda, H. Ohe, N. Asakawa, Y. Yoshida and T. Sato, J. Pharm. Biomed. Aral., 12, 557 (1994).

13. Y. Oda, N. Mano, N. Asakawa, Y. Yoshida, T. Sato and T. Nakagawa, Anal. Sci., 9, 221 (1993).

14. E. Domenici, C. Bertucci, P. Salvadori and I. W. Wainer, J. Pharm. Sci., 80, 164 (1991).

15. T. A. G. Noctor, M. J. Diaz-Perez and I. W. Wainer, J. Pharm. Sci., 82, 675 (1993).

16. N. Mano, Y. Oda, N. Asakawa, Y. Yoshida, T. Sato and T. Miwa, J. Chromatogr., 687, 223 (1994).

17. C.-S. Chen, T. Chen and W.-Ru Shieh, Biochim. Biophys. Acta, 1033, 1 (1990).

18. M. M. Bradford, Anal. Biochem., 72, 248 (1976).

19. T. A. G. Noctor, I. W. Wainer and D. S. Hage, J. Chromatogr., 577, 305 (1992).

20. B. Loun and D. S. Hage, Anal. Chem., 66, 3814 (1994). 